\title{
ASSESSMENT OF THE FOREST HEALTH THROUGH REMOTE SENSING TECHNIQUES IN VALEA ROȘIE NATURA 2000 SITE, BIHOR COUNTY, ROMANIA
}

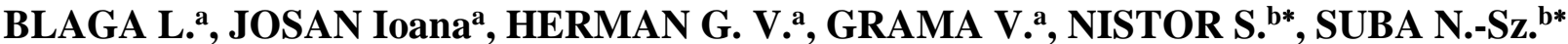

\begin{abstract}
${ }^{a}$ University of Oradea, Faculty of Geography Tourism and Sport, 1 University Street, 410 087, Oradea, Romania, E-mails: blagalucian2012@gmail.com, ioanajosan2012@ gmail.com, grigoreherman@ yahoo.com, vasile.grama2014@gmail.com
\end{abstract}

\author{
${ }^{\mathrm{b}}$ University of Oradea, Faculty of Constructions, Cadastre and Architecture, Department of Cadastre and Architecture, 4 B. St. \\ Delavrancea, 410058, Oradea, Romania, e-mails*: sonistor@uoradea.ro; suba norbert@yahoo.com
}

Received: 09.09.2019 / Accepted: 09.10.2019/ Revised: 01.11.2019 / Available online: 10.12.2019

DOI: 10.2478/jaes-2019-0029

KEY WORDS: forest health, Nature 2000, Structure Insensitive Pigment Index, Normalized Difference Vegetation Index

\begin{abstract}
:
The present study deals with the estimation of the evolution tendency of the environmental stage of a protected habitat with predominant forest vegetation, during a short period of time, using techniques specific to remote sensing. Therefore, two important spectral indexes were tested while assessing the health of the forest ecosystems: i.e. the Normalized Difference Vegetation Index (NDVI) and the Structure Insensitive Pigment Index (SIPI). The period of time taken into consideration for the study was, 2013 - 2019 , having used medium resolution satellite photos, Landsat 8 OLI, having initially undergone standard pre-processing operations (resize data, radiometric calibration, atmospheric correction). The satellite images modified according to the Top of Atmosphere Reflectance and corrected topographically resulted into getting values for the two before mentioned indexes. The quantity-spatial results obtained, correlated to the monthly values of the precipitations processed in order to obtain the SPI (Standardized Precipitation Index), mostly reveal, in what SIPI and also NDVI are concerned, a slight decrease in the quality of the forest on the analysed area in the sense that the vegetation stress is increased under meteorological factors, expressed differently depending on the morphometric and pedological parameters of the habitat.
\end{abstract}

\section{INTRODUCTION}

The pressure of the anthropic and natural stress factors on the forest territories and consequently on the protected habitats which comprise most of these surfaces has constantly risen during the past decades. It manifests itself either directly or indirectly in different ways, which were minutely dealt with ans analysed in the academic literature: deforestations, changes in the use of the land, fires, unsustainable management, air pollution, climatic changes, drought, increased predisposition to pests and pathogenic agents (Andronache et al., 2019; Lausch et al., 2016; Romocea et al., 2018; Herman et al., 2019).

The forest health concept arises as a natural consequence of this reality, being first defined by Leopold (1949), and rigorously considered during the '90s (Kolb et al., 1991), practically providing a common rational base for the great variety of studies and methods which tried to assess, quantify and monitor the health of the forest ecosystems.
Even if the meaning and connotations of the concept may be interpreted from a multiple, economic, social, environmental perspective (Tuominen et al., 2008), they are all interconnected and they are all based on one common element: the normal process of a forest environment.

Moreover, the problem being rather important, the health of the forests nowadays is assessed in unitary and coherent working structures and fluxes integrated in hierarchical levels of complexity. Romania for example, is a member of the systematic transnational network (Level I) and the intensive monitoring network (Level II) oh the health of forests at a European level with 262 level I researches and 12 permanent Level II researches carried out. If the location of the 12 intensive monitoring stations is considered, it may be observed that in the Western part of Romania there is one location, i.e. in Stâna de Vale, which is dedicated to spruce tree.

Remote sensing methods and techniques offer major support not only for the investigations carried out on the level of working stations already implemented in the field, but also for the 
gathering of data related to the health of forests which are found in areas where such stations are missing.

This exact objective has been considered as the starting point of our study, respectively the estimation of the evolutionary tendency of the environmental health in a protected habitat with dominant forest vegetation, during a short period of time. Additionally, we wanted to test two spectral indexes which are considered to be important for the assessment of $\mathrm{FH}$ (forest health) in the NV part of Romania.

\section{STUDY AREA}

The Natura 2000 Valea Roșie community interest site is situated in the North-Western part of Romania, in the administration of Bihor County (Figure 1), occupying a 786 ha surfce (Herman et al., 2016a, b; Ilieș et al., 2017; http://natura2000.eea.europa.eu/Natura2000/SDF.aspx?site=RO SCI0267). The geomorphologic support is provided by the hilly landscape specific for the Hills of Oradea, with average altitudes of around $220 \mathrm{~m}$, with alternating narrow interfluves with large valleys and evolved slopes having a complex profile, all being the result of river modelling, seldom intermittently, combined with slope processes.

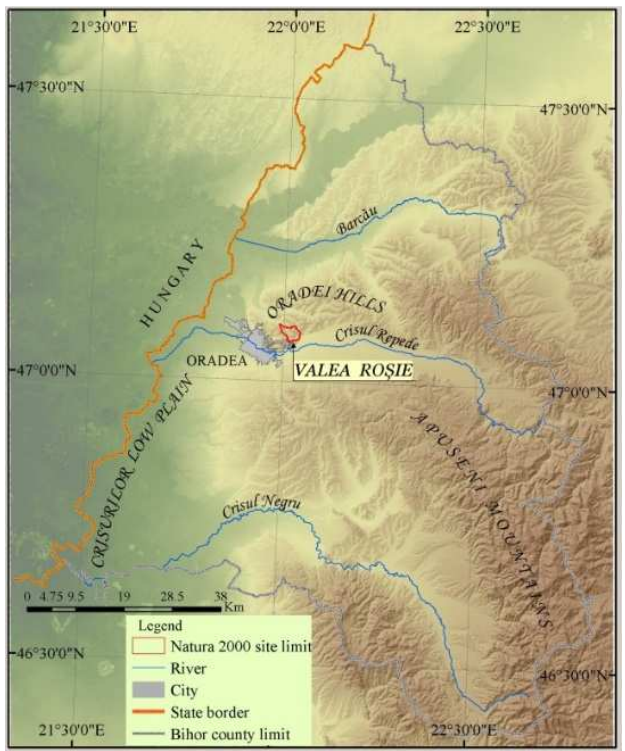

Figure 1. Study area location

Considering the natural and cultivated vegetation categories present it may be observed that $95.87 \%$ of the surface of the site is covered by broad-leaved trees which are specific to temperate climate, $0.35 \%$ is covered by bushes and shrubs, while the rest is covered by agricultural fields represented by ploughable fields, pastures and orchards (Detailed report of biodiversity assessment for ROSCI0267 Red Valley, 2016).

Given the importance of these aspects for the proposed rational procedure, we have tried to observe with the use of otrhophotoplans received from the geoportal ANCPI website, together with the VHR Pleiades images from the Copernicus data base, if changes had occurred regarding the destination of the land, changes which do not take into account the human factor, i.e. if the forest either extended or retracted during the study period (2013 - 2019). There are no essential changes, only a slight accentuation in the loss of the grass spread surrounding the access ways, as it may be observed in detail in figure 2 .
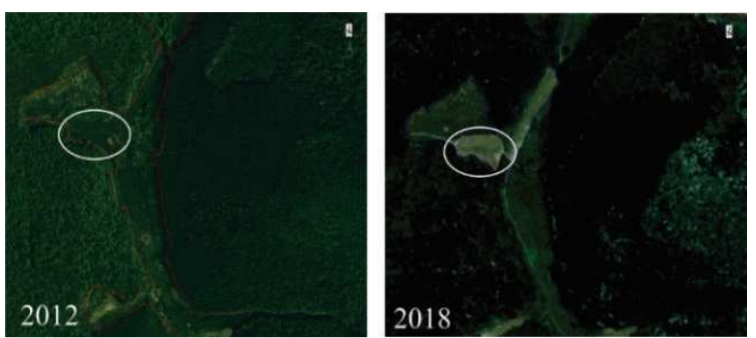

Figure 2. Slight vegetation changes in the NV part of Valea Roșie site (Data sources: orthophoto ANCPI 2012, Pleiades VHR 2018)

\section{MATERIALS AND METHODS}

The working method presented in the study is situated in the empirical modelling domain, which is based on the statistic relation between one or more biotic features and certain spectral variables which answer to the changes of the biotic features taken into consideration (Lausch et al., 2017).

The category of spectral indexes which may be used in this modelling is extremely large and varied, being mainly conditioned by the type of satellite images used as input data, as well as by the objective. Their description and applicability may be found in different articles, either making a synthesis (Bannari et al., 1995; Chen, 1996; Xue et al., 2017), or dedicated to specific researches (Agapiou et al., 2012; Heiskanen et al., 2013; Avola et al., 2019).

In essence, they are grouped in seven large classes (Envi Help, Pettorelli, 2013) based on the properties similarities criterion: Broadband Greenness, Narrowband Greenness, Canopy Nitrogen, Canopy Water Content, Dry or Senescent Carbon, Leaf Pigments, Light Use Efficiency.

For the present study, two spectral indexes were chosen: the Normalized Difference Vegetation Index (NDVI) and the Structure Insensitive Pigment Index (SIPI).

NDVI is comprised by the Broadband Greenness class and is the best known one, respectively most used spectral index for the estimation of the typological, physiological and phenological features of green vegetation (Jiang et al., 2006; Jiang and Huete, 2010; Xu and Guo, 2014).

Rouse et al. (1973) have revealed that through the combination of RED and NIR channels, based on the principle that green plants (containing chlorophyll) absorb radiations in the red spectrum (Red) and reflect radiation from the near infrared spectrum (Near Infrared):

$$
N D V I=\frac{N I R-R E D}{N I R+R E D}
$$

Its values are comprised between +1 and -1 , while for the vegetation the values are usually between 0.3 and 1 . As it gets closer to 1 , both the vitality and the health of the vegetation improve. 
NDVI indicates rather accurately the chlorophyll content as well as defoliation, reason for which is frequently used in studies such as the present one (Pettorelli et al., 2005; Xiao and McPherson, 2005; Reid et al., 2016).

SIPI is a type of index highlighted by Penuelas et al. (1995), based on the premise that both the chlorophyll and the carotenoids absorb radiation from the red spectrum, but carotenoids alone absorb radiations in the blue spectrum. He demonstrated the correlation between the values of the differences (NIR - Blue) and (NIR - Red) from the radiation spectrum reflected by the vegetation, on the one hand, and that between carotenoids and chlorophyll on the other hand, under conditions of medium and high plant pigmentation concentration:

$$
S I P I=\frac{N I R-B l u e}{N I R+R E D}
$$

Its values alternate between 0 and 2 , while the common range for the healthy green vegetation is comprised within 0.8 and 1.8 , the rule for their interpretation being the following: the higher the values of the index, the greater the stress on the level of the canopy. The insensitive term makes reference to its decreased sensitivity to the variability of the structure of the canopy, reason for which the term is dedicated for such vegetal forest associations.

Four types of various vegetation were tested in different environmental conditions obtaining good correlative results (Tuominen et al., 2008; Verrelst, 2010; Yang et al., 2017) or poorer results (Sims and Gamon, 2002; Shah et al., 2019).

In order to obtain the indexes, medium resolution satellite snapshots were used $(30 \mathrm{~m})$ Landsat 8 OLI/TIRS comprised between $2013 \quad-\quad 2019$, acquired from https://earthexplorer.usgs.gov, while for pixels validation with forest vegetation, ANCPI orthophotoplans, high resolution multispectral images were used (Pleiades, 2014, 2016, 2018, 160 $\mathrm{cm}$ resolution for Blue, Green, Red and NIR, respectively $40 \mathrm{~cm}$ for panchromatic) acquired from https://spacedata.copernicus.eu, adding naturally the activity carried out on site.

A Landsat 8 satellite image from the month of August was chosen for each separate year, as the period 15th of July 31 st of August is considered (in Romania) to be a period with a peak of physiological activity of the forest and it is also the period when the stress factors apply a maximum pressure on the trees, according to the Report on the state of the forests in Romania in 2017, written by the Ministry of Waters and Forests.

If qualitatively, they did not comply with the conditions meant to ensure a thorough pre-processing and processing, they were eliminated. We consider here the case of the snapshots taken in 2014 and 2016, which could not be used due to their high degree of nebulosity, thus from the 2013 - 2016 series only the multispectral data from the years 2013, 2015, 2017, 2018 and 2019 remained.

\section{RESULTS AND DISCUSSIONS}

The 5 Landsat 8 snapshots were put in the first phase through standard pre-processing operations: resize data, radiometric calibration, atmospheric correction and topographic correction.
The first operation was required to reduce the images as close as possible to the working surface, as it may be seen in the example given in Figure 3.

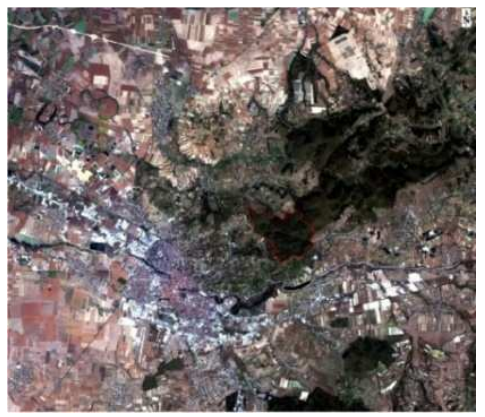

Figure 3. Resize data for Landsat 8 OLI, 2019-08-10 (Data source: https://earthexplorer.usgs.gov)

Data conversion from a DN format (Digital Number) in radiation values with a scale factor of 0.1 was carried out through radiometric calibration, which is practically dedicated for the FLAASH module (Fast Line-of-sight Atmospheric Analysis of Spectral Hypercubes) of the Envi software.

The Atmospheric Correction implies the transformation of the radiation values into reflectance values for all the snapshots and was carried out using the FLAASH module. Before the effective use to obtain NDVI and SIPI, the derived materials (ToA - Top of Atmosphere Reflectance) were put through a topographic correction process in order to decrease the shadowing effect.

All the derived autotype images for NDVI and SIPI were classified in the first step by using threshold values indicating the passage from a set of values to another (natural breaks method), while at the end undergoing a supervised classification process, which has taken into consideration the real value of the data set and the relevance of the classes for the proposed procedure, starting thus from the results of other researches mentioned hereinbefore.

A general analysis of the NDVI on all the 5 analysed years (Figures 4 and 5), it may be observed that the values are well grouped on a deviation comprised between 0.46 and 0.91 , which is absolutely normal, and also validates the correctness of the processing of satellite snapshots. The average value of NDVI for each raster oscillates around 0.8 , with small differences (from 0.847 to 0.816 ) which only have statistic relevance.

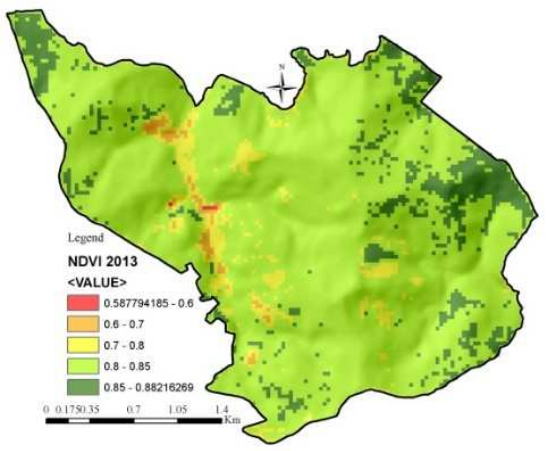

Figure 4. NDVI 2013 


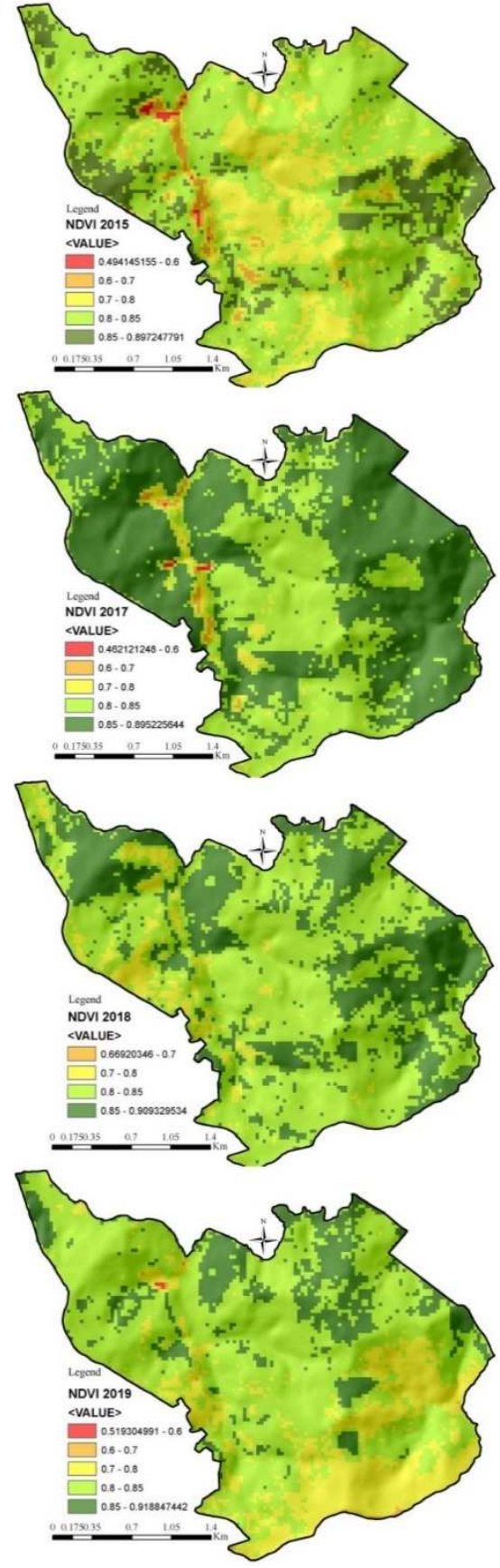

Figure 5. NDVI: 2015- 2019

The class which has an established limit of 0.6 (class I in Table 1) corresponds to the surfaces where there is no vegetation or if there is a little, there is a mixture of pixels representing grassy and wood vegetation and another type of surface, namely access ways. Our objective was not to hide this type of pixels or to extract only those representing forest vegetation, but to test the behaviour of the indexes for different structure of the ground surface on an area where they haven't been used before. At the level of class $0.6-0.7$ there if a combination of pixels between grassy vegetation, bushes and forest vegetation as well as unpaved roads, partially covered by the canopy. Classes 0.8 0.85 and over 0.85 are specific to the forest ecosystems with a normal optimum activity.
Class $0.7-0.8$ (class III in Table 1) is the one which was considered to be the most important as it may be fully engrafted on the territory covered by forest, while the value of NDVI is practically at the lower normal limit for the summer period (see the results of multiple monitoring carried out for temperate forest ecosystems by Ryu et al., 2014, Yang et. al., 2017). In conclusion, the spatial variations may bring sets of information regarding the behaviour of the forest considering the stress factors. In other words, it has been wanted to highlight the fact that the intrinsic change of the values is not so important as the habitat taken into consideration is a protected one, where no economic activity which might affect the balance of the forest is allowed, but the extension or minimisation of the habitats of the classes and mainly of the class $0.7-0.8$, which may give clues regarding the behavioural stress of the studied ecosystem with implications on the health of the forest.

In table 1, which illustrates forward the way in which the distribution of NDVI classes in the analysed territory varies, it may be observed that on the level of class III $(0.7-0.8)$ there are the most extensive/considerable changes, with sudden leaps from one year to another, but also with an increasing tendency compared to 2013 (except for the year 2017, with a more than accentuated decrease and 2018 with an almost stable situation on a slight decrease). Clearly, the surfaces from 2015 and 2019 stand out, namely 178 ha and 179 ha, seen in the first instance as atypical for the row of data. The causes, respectively the factors which may induce such leaps, shall be dealt with after having presented the situation for SIPI.

In compensation, there is a decreasing rend of the surface of class IV (0.8 - 0.85) with a minimum at the level of 2017 and a slight come-back for 2018 and 2019.

Table 1. Surface distribution of value classes for NDVI

\begin{tabular}{|c|c|c|c|c|c|}
\hline $\begin{array}{c}\text { Class } \\
\text { values } \\
\text { for } \\
\text { NDVI }\end{array}$ & $\begin{array}{c}\text { NDVI } \\
2013 \\
\text { (ha) }\end{array}$ & $\begin{array}{c}\text { NDVI } \\
2015 \\
\text { (ha) }\end{array}$ & $\begin{array}{c}\text { NDVI } \\
2017 \\
\text { (ha) }\end{array}$ & $\begin{array}{c}\text { NDVI } \\
2018 \\
\text { (ha) }\end{array}$ & $\begin{array}{c}\text { NDVI } \\
2019 \\
\text { (ha) }\end{array}$ \\
\hline I & 0.45 & 2.97 & 0.9 & & 0.36 \\
\hline II & 9.27 & 15.66 & 5.49 & 0.27 & 2.52 \\
\hline III & $\mathbf{5 2 . 0 2}$ & $\mathbf{1 7 8 . 2}$ & $\mathbf{2 6 . 7 3}$ & $\mathbf{5 0 . 4 9}$ & $\mathbf{1 7 9 . 1 9}$ \\
\hline IV & 631.17 & 464.48 & 280.44 & 462.23 & 473.67 \\
\hline V & 93.96 & 125.55 & 473.3 & 273.86 & 131.12 \\
\hline
\end{tabular}

In what the transfer of the values from one pixel to another is concerned, or in other words, the transfer of forest habitats from one class value to another, in order to obtain a more detailed image, the Tabulate Area processes were carried out between the set of data obtained for 2013 and the one for 2017, the areas being defined after the extension of the classes from NDVI 2013, respectively between NDVI 2017 and NDVI 2019, with areas defined considering the set for 2017 (Tables 2, 3).

Therefore, it is noticeable that at the level of classes I and II ther is a relative balance, in the sense that a large proportion of the pixels comprised by these classes in 2013 and 2017 are the same for 2019 as well, which is absolutely normal if their composition is taken into consideration. 
Table 2. Tabulate Area between NDVI 2013 and NDVI 2017

\begin{tabular}{|c|c|c|c|c|c|}
\hline \multirow{2}{*}{$\begin{array}{c}\text { NDVI } 2013 \\
\text { Classes }\end{array}$} & \multicolumn{5}{|c|}{ NDVI 2019 Classes (ha) } \\
\cline { 2 - 6 } & I & II & III & IV & V \\
\hline I & 0.36 & 0.09 & 0 & 0 & 0 \\
\hline II & 0.36 & 4.32 & 4.5 & 0.09 & 0 \\
\hline III & $\mathbf{0 . 1 8}$ & $\mathbf{1 . 0 8}$ & $\mathbf{1 7 . 5 5}$ & $\mathbf{2 9 . 5 2}$ & $\mathbf{3 . 6 9}$ \\
\hline IV & 0 & 0 & 4.32 & 243.27 & 383.58 \\
\hline V & 0 & 0 & 0.36 & 7.56 & 86.04 \\
\hline
\end{tabular}

Table 3. Tabulate Area between NDVI 2017 and NDVI 2019

\begin{tabular}{|c|c|c|c|c|c|}
\hline \multirow{2}{*}{$\begin{array}{c}\text { NDVI } 2017 \\
\text { Classes }\end{array}$} & \multicolumn{5}{|c|}{ NDVI 2019 Classes (ha) } \\
\cline { 2 - 6 } & I & II & III & IV & V \\
\hline I & 0.09 & 0 & 0.63 & 0.18 & 0 \\
\hline II & 0.27 & 0.54 & 4.59 & 0.09 & 0 \\
\hline III & $\mathbf{0}$ & $\mathbf{0 . 8 1}$ & $\mathbf{1 4 . 5 8}$ & $\mathbf{1 0 . 2 6}$ & $\mathbf{1 . 0 8}$ \\
\hline IV & 0 & 1.08 & 79.38 & 176.4 & 23.58 \\
\hline V & 0 & 0.09 & 80.01 & 286.74 & 106.47 \\
\hline
\end{tabular}

Considering the 52 ha of class III in 2017 , only 11.55 ha were maintained for 2017, 56\% from the initial class migrating towards class IV, while from the 26.7 ha of 2017 , only $54.6 \%$ have been maintained for 2019 , even if this class has a record surface towards the end of the year.

There are redistributions between classes IV and V regardless of the years compared, but in fact they are classes close to each other and have the same positive significance for the health of the studied forest ecosystem. Class III also takes part in these transfers of surfaces between classes IV and V, especially between 2017 and 2019, in the sense of taking over a series of surfaces.

For SIPI the values oscillate between a minimum of 0.85 and a maximum of 1.2 during the entire analysed period (Figure 6 and 7 ), while the average on a raster level stagnates within a range comprised between 0.92 and 0.97 . The interpretation of the values is reversed considering NDVI, as it has already been mentioned, but from the same considerations stated for the analysis of NDVI, the changes for classes III (0.95 - 0.98) and especially IV $(0.98-1)$ are relevant.

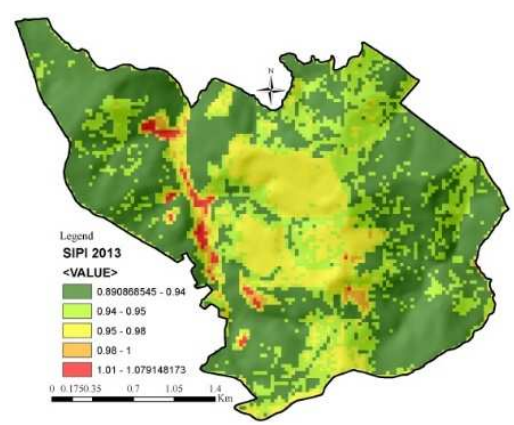

Figure 6. SIPI 2013

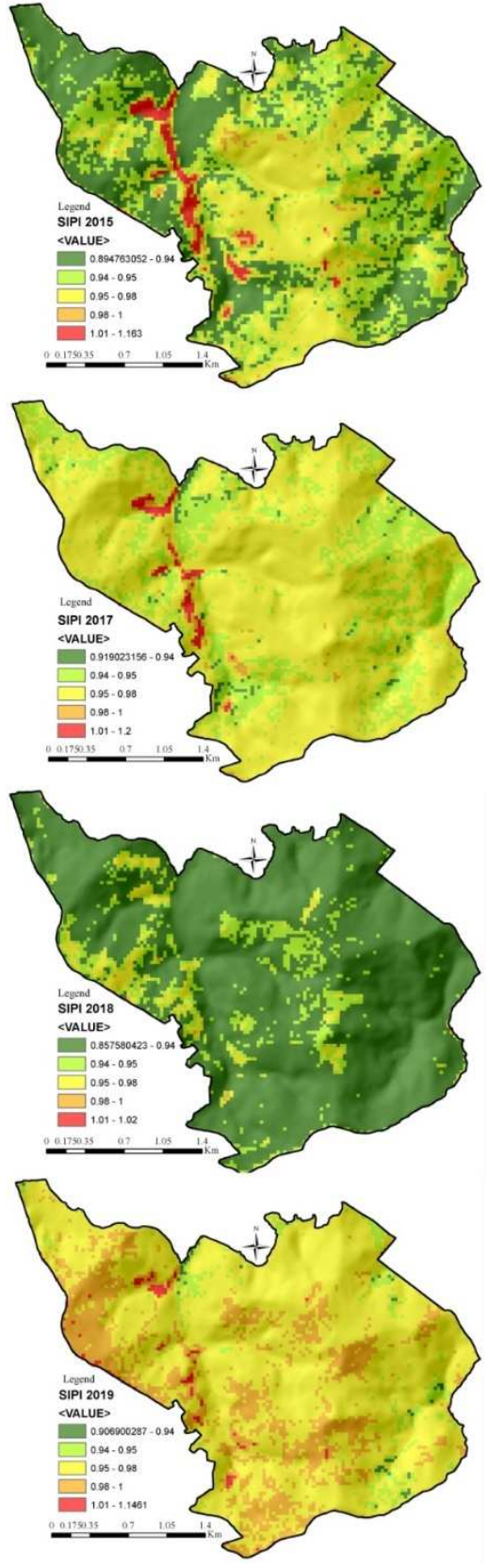

Figure 7. SIPI: 2015- 2019

At the level of the latter (Table 4), it may be observed that from 2013 to 2017 the surface remained roughly constant, followed by a rather accentuated fluctuation marked by a sudden drop under 1 ha for 2018 and a spectacular increase with over 170 ha in 2019. The surface of class III has an almost continuous increase with the exception of the same 2018 reaching 569 ha in 2019, becoming thus a predominant class in the studied site. Practically, the year 2018 has an atypical behaviour in relation to other years, both on the level of SIPI data as well as on the level of NDVI data. 
Table 4. Surface distribution of value classes for SIPI

\begin{tabular}{|c|c|c|c|c|c|}
\hline $\begin{array}{c}\text { Class } \\
\text { values } \\
\text { for } \\
\text { SIPI }\end{array}$ & $\begin{array}{c}\text { SIPI } \\
\text { (ha) }\end{array}$ & $\begin{array}{c}\text { SIPI } \\
2015 \\
\text { (ha) }\end{array}$ & $\begin{array}{c}\text { SIPI } \\
2017 \\
\text { (ha) }\end{array}$ & $\begin{array}{c}\text { SIPI } \\
2018 \\
\text { (ha) }\end{array}$ & $\begin{array}{c}\text { SIPI } \\
2019 \\
\text { (ha) }\end{array}$ \\
\hline I & 434.43 & 271.74 & 12.69 & 666.18 & 4.5 \\
\hline II & 192.78 & 217.92 & 184.95 & 80.37 & 31.14 \\
\hline III & $\mathbf{1 3 8 . 3 3}$ & $\mathbf{2 6 1 . 0 5}$ & $\mathbf{5 6 6 . 6 4}$ & $\mathbf{3 9 . 3 3}$ & $\mathbf{5 6 9 . 6 1}$ \\
\hline IV & $\mathbf{1 2 . 9 6}$ & $\mathbf{1 5 . 5 6}$ & $\mathbf{1 1 . 8 8}$ & $\mathbf{0 . 8 1}$ & $\mathbf{1 7 3 . 1 6}$ \\
\hline V & 8.37 & 19.54 & 10.71 & 0.18 & 8.46 \\
\hline
\end{tabular}

The redistribution of the pixels on the classes' level was followed using the same technique and the same years as for the NDVI.

Table 5. Tabulate Area between SIPI 2013 and SIPI 2017

\begin{tabular}{|c|c|c|c|c|c|}
\hline \multirow{2}{*}{$\begin{array}{c}\text { SIPI } 2013 \\
\text { Classes }\end{array}$} & \multicolumn{5}{|c|}{ SIPI 2017 Classes (ha) } \\
\cline { 2 - 6 } & I & II & III & IV & V \\
\hline I & 12.69 & 177.84 & 243.36 & 0.54 & 0 \\
\hline II & 0 & 7.11 & 185.4 & 0.18 & 0.09 \\
\hline III & 0 & 0 & 133.56 & 3.87 & 0.9 \\
\hline IV & $\mathbf{0}$ & $\mathbf{0}$ & $\mathbf{4 . 0 5}$ & $\mathbf{5 . 8 5}$ & $\mathbf{3 . 0 6}$ \\
\hline V & 0 & 0 & 0.27 & 1.44 & 6.66 \\
\hline
\end{tabular}

Table 6. Tabulate Area between SIPI 2017 and SIPI 2019

\begin{tabular}{|c|c|c|c|c|c|}
\hline \multirow{2}{*}{$\begin{array}{c}\text { SIPI } 2017 \\
\text { Classes }\end{array}$} & \multicolumn{5}{|c|}{ SIPI 2019 Classes (ha) } \\
\cline { 2 - 6 } & I & II & III & IV & V \\
\hline I & 1.62 & 3.87 & 7.11 & 0.09 & 0 \\
\hline II & 2.43 & 17.1 & 145.08 & 20.16 & 0.18 \\
\hline III & 0.45 & 10.17 & 413.1 & 140.67 & 2.25 \\
\hline IV & $\mathbf{0}$ & $\mathbf{0}$ & $\mathbf{3 . 2 4}$ & $\mathbf{7 . 3 8}$ & $\mathbf{1 . 2 6}$ \\
\hline V & 0 & 0 & 1.08 & 4.86 & 4.77 \\
\hline
\end{tabular}

There is an pronounced/marked discrepancy between the homogeneity of the classes from 2013 and 2017 which arises from the general picture of the data comprised in Tables 5 and 6 (there is an almost complete transfer between class II and class III), in contract to the spatial heterogeneity of the values from 2013 and 2019. From the 12.96 ha from class IV in 2013, only 3.24 ha remained in 2019 although for 2019 a record surface was recorded for the range $0.98-1$ (173.16 ha). Moreover, it is to be noticed that for class II (0.94 - 0.95), from the 192.78 ha in 2013 , only 2.43 ha are kept in 2019 , the rest of the pixels belonging to this class having migrated to class III $(0.98-1)$.

What are the causes of these sequential fluctuations on a short time span (7 years), with a tendency to expand their surface of the classes taken into consideration by the study as an indicator of the increase of stress for the forest ecosystem taken into consideration?

The premise considered for this casual-explanatory case is based on the axiom that most of the time there are more stimuli, but there is always one with the role of command, namely the main one.

The only can record rapid fluctuations from one year to another or from one month to another are the meteorological ones. Therefore, we have chosen the precipitations which we considered to be essential in explaining the problem previously formulated.

A series of data comprising monthly precipitations (absolute and average values) was considered for processing, data mainly from Bihor County Statistical Yearbook, their source being the National Meteorological Administration. For the years 2018 and 2019 (until October) the data was taken and processed from the archive of the weather station of Oradea Airport archive (https://rp5.ru/Arhiva_meteo_\%C3\%AEn_Oradea_(aeroport).

A first step has taken into consideration the time interval between 2013 and 2019 for the processed satellite snapshots (Figure 8).

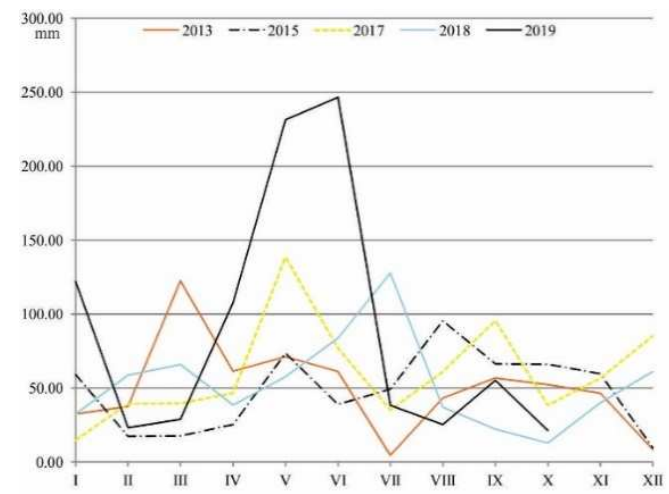

Figure 8. Monthly precipitations, 2013 - 2019

Their advancement, respectively the simple oscillations from one month to another cannot even offer partial explanations for the results brought forward so far for NDVI and SIPI. They offer a general image, already known, regarding the general decrease of the quantity of precipitations after June except for 2018. The precipitations values for July 2018 correlate perfectly with the increased values of NDVI as well as with the low values of SIPI for that exact year. This aspect is better highlighted if the amount of precipitations for July and August for the 2013 and 2019 interval are taken into account (Figure 9).

Furthermore, a data set from the same category considering a 20 year interval (2000 - 2019) were taken into consideration on which the Standard Precipitation Index was processed.

The Standardized Precipitation Index (SPI) was developed by McKee et al. (1993) and it is recommended by the WMO (World Meteorological Organization), through the Lincoln Declaration (Hayes et al., 2011) in order to highlight the meteorological drought.

It is practically designed to quantify the precipitation deficit for multiple time scales, using algorithms, and it also provides information about the humidity periods.

As SPI is transformed into a normal distribution, the average value for the analysed data set is considered to be 0 , the positive values show that they are higher than the median while the negative ones indicate that they are smaller than the median of the precipitation row (SPI User Guide, 2012). 
Considering the present study, we are interested in these exact deviations from the normal distribution, in order to correlate them with the values of the 2 processed spectral indexes, and not the effective identification of the drought periods.

The data set used meets the requirements of a correct processing of SPI because the SPI User Guide recommends values for the precipitations for $20-30$ years, even if McKee et al. (1993) makes reference to an optimum of approximately 30 years, while Guttmann (1994) claims that an interval of $50-60$ years would be preferable.

The SPI was determined through the aggregation of the data obtained during $1,2,3$, and 6 months, options considered to be relevant for revealing the water deficit in the ground and for highlighting the meteorological or agricultural drought.

The values for 1-month SPI and 2-Month SPI were best correlated to the SIPI data, but we are going to consider the 2month SPI, a sequence of the results being graphically represented in Figure 10.

Therefore, in 2013 there were 3 months containing positive deviations (March until May), followed by 4 months with negative deviations, with a minimum of (-1.86) in July. Before the 3 months which contain a positive SPI, 2011 and 2012 almost entirely contain negative deviations from the median. The consequence is that, for SIPI, class III is well individualised $(0.95$ - 0.98), while for NDVI it barely starts to show, but it is observed how the class above 0.85 appears insularly.

2015 for SPI is a year with negative deviations starting with February until July. Starting with August there is a straightening of the values for the following 4 months, but because the satellite data are from this exact month the effects are no longer visible. Therefore, class III is extended for SIPI and class IV is better individualised. The same extension of class III is also observed for NDVI.

2017 is mainly a year with positive deviations, but for July when it has been observed a negative deviation. The values for NDVI straighten but for SIPI they practically reveal an accentuation of the stress of forest vegetation to the weather factor.

There has been recorded an asymmetric pluviometrical behaviour for 2018 which is extremely contrasting, in the sense that the deviations during the first 7 months were positive or close to the median, while starting from August the deviations were negative until December. July is also highlighted (with +1.17 ) as in the graphic representation of the precipitations. In effective values, July 2018 means $127.6 \mathrm{~mm}$ precipitations. Starting with 2001 until the present, only 2 such levels were recorded in this month, i.e. once in 2011 and once in 2014. The effect is one where atypical situations appear, both in SIPI as well as in NDVI (Figures 5 and 7).

The behaviour for 2019 (until October) is more unbalanced than 2018 considering the repartition of the values. There are 6 months with positive deviations, where June has a deviation of +3.09 , and July +2.2 . August follows with a negative deviation of -1.33 . In practical values, the precipitations for June amounted to 246.4 (an absolute record for the studied time period), followed by July and August where the precipitations amounted to $38 \mathrm{~mm}$ and 25 $\mathrm{mm}$, respectively. Hence, an additional extreme physiological stress on the vegetation, mainly on the forest vegetation. The result is clearly visible for SIPI and also for NDVI (Figures 5 and 7).

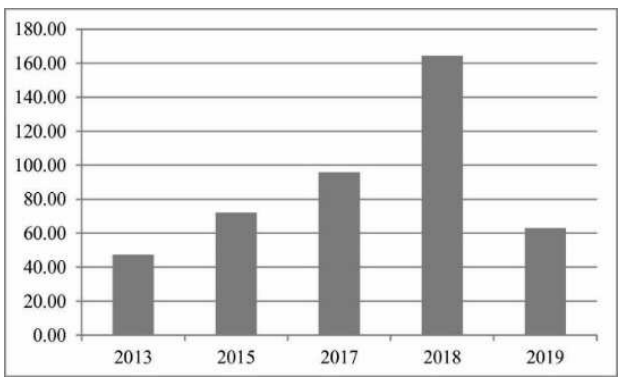

Figure 9. The amount of precipitations for July - August (2013 $-2019)$

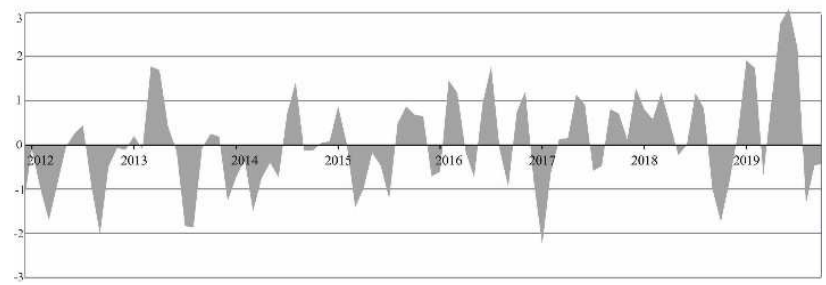

Figure 10. The sequence of the SPI for $2012-2019$

Why isn't this meteorological stress felt uniformly at the level of the forest in Valea Roșie site?

It is possible to find an explanation within the morphologic and pedological features of the studied territory. In order to exemplify and prove a point in the same time, a morphometric index was chosen but which is able to offer clues related to the accumulation of water in the ground depending on the position on the field and on the the slope.

The Beven and Kirkby (1979) Topographic Wetness Index (TWI) has thus been taken into consideration, index obtained in SAGA based on an elevation model with a $10 \mathrm{~m}$ resolution (Figure 11).

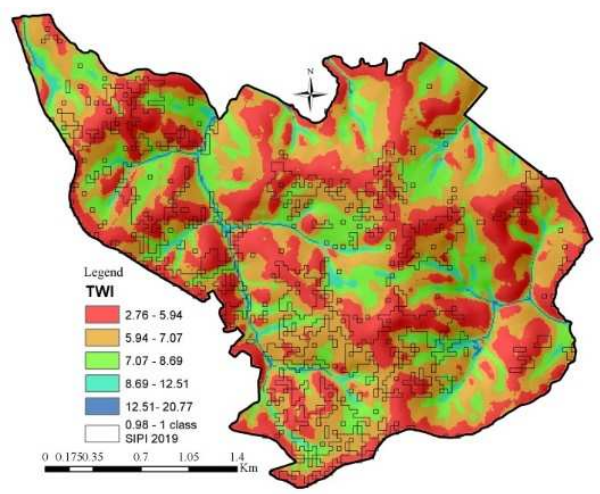

Figure 11. TWI

By comparing class 0.98 - 1 from SIPI 2019, with those classes indicating the lowest water accumulation potential $(2.76-5.94$ and $5.94-7.07$ ), it results that $82.33 \%$ of SIPI class IV overlays with two inferior TWI classes. 


\section{CONCLUSIONS}

The following aspect arises from the results related to the objectives of the study:

- $\quad$ SIPI compared to NDVI is a more sensitive index, in the sense that it better reflects the physiologic behaviour of the forest in the analysed habitat;

- $\quad$ The recorded values, both for SIPI as well as for NDVI, are comprised within the normal relative limits for the forest, namely no proof that we are dealing with an ecosystem in degradation;

- There is a clear increase in stress levels conditioned firstly from a meteorological point of view, the main main reason being the values of 2019, especially for SIPI;

- It has to be observed in the following years if this increasing trend of the stress of forest vegetation for the analysed data in 2013, 2015, 2017 and 2019 will become a statistical-mathematical tendency.

\section{References:}

Agapiou, Athos, Diofantos G. Hadjimitsis, and Dimitrios D. Alexakis. 2012. "Evaluation of Broadband and Narrowband Vegetation Indices for the Identification of Archaeological Crop Marks." Remote Sensing. https://doi.org/10.3390/rs4123892.

Andronache, I., Marin, M., Fischer, R., Ahammer, H., Radulovic, M., Ciobotaru, A. M., ... \& Herman, G. V. (2019). "Dynamics of forest fragmentation and connectivity Using particle and fractal Analysis". Scientific reports, 9(1), 1-9.

Anuarul Statistic al Judeţului Bihor, 2018, Institutul Național de Statistică, Direcția Județeană de Statistică Bihor (Bihor County Statistical Yearbook, 2018, National Institute of Statistics, Bihor County Direction Of Statistics)

Avola, Giovanni, Salvatore Filippo Di Gennaro, Claudio Cantini, Ezio Riggi, Francesco Muratore, Calogero Tornambè, and Alessandro Matese. 2019. "Remotely Sensed Vegetation Indices to Discriminate Field-Grown Olive Cultivars." Remote Sensing. https://doi.org/10.3390/rs11101242.

Bannari, A, D Morin, F Bonn, and A R Huete. 1995. "A Review of Vegetation Indices - Remote Sensing Reviews." Remote Sensing Reviews. https://doi.org/10.1080/02757259509532298.

Beven, K. J., and M. J. Kirkby.1979. "A Physically Based, Variable Contributing Area Model of Basin Hydrology." Hydrological Sciences Bulletin. https://doi.org/10.1080/02626667909491834.

Chen, Jing M. 1996. "Evaluation of Vegetation Indices and a Modified Simple Ratio for Boreal Applications." Canadian Journal of Remote Sensing. https://doi.org/10.1080/07038992.1996.10855178.

Guttman, Nathaniel B. "On the sensitivity of sample L moments to sample size." Journal of climate 7, no. 6 (1994): 1026-1029.

Hayes, Michael, Mark Svoboda, Nicole Wall, and Melissa Widhalm. "The Lincoln declaration on drought indices: universal meteorological drought index recommended." Bulletin of the American Meteorological Society 92, no. 4 (2011): 485-488.
Heiskanen, Janne, Miina Rautiainen, Pauline Stenberg, Matti Mõttus, and Veli Heikki Vesanto. 2013. "Sensitivity of Narrowband Vegetation Indices to Boreal Forest LAI, Reflectance Seasonality and Species Composition." ISPRS Journal of Photogrammetry and Remote Sensing. https://doi.org/10.1016/j.isprsjprs.2013.01.001.

Herman, G. V., Ilieș, D. C., Baias, Ș., Măduța, M. F., Ilieș, A., Wendt, J., \& Josan, I. (2016a). "The tourist map, scientific tool that supports the exploration of protected areas, Bihor County, Romania". GeoSport for Society, 4(1): 24-32

Herman, G. V., Ilieș, D. C., Măduța, M. F., Ilieș, A., Gozner, M., Buhaș, R., \& Mihók-Géczi, I. M. T. (2016b). "Approaches regarding the importance of Natura 2000 sites' settings pupil's education through geography. Case study: Valea Rose (Red Valley) Natura 2000, Bihor country, Romania”. Journal of Geography, Politics and Society, 6(4), 57-62.

Herman, G., Ilies, D., Gaceu, O., Ilies, A., Mester, C., Ilies, M., ... \& Dumitru, M. (2019). "Some Considerations Concerning the Quality of Groundwater in the Natura 2000 Lunca Barcaului (Barcaului Meadow) Site, Romania". Journal of Environmental Protection and Ecology, 20(3), 1102-1109.

Ilieș, D. C., Baias, S., Buhaș, R., Ilieș, A., Herman, G. V., Gaceu, O., ... \& Măduța, F. (2017). "Environmental education in protected areas. Case study from Bihor County, Romania". GeoJournal of Tourism and Geosites, 19(1), 126-132.

Jiang, Zhangyan, Alfredo R. Huete, Jin Chen, Yunhao Chen, Jing $\mathrm{Li}$, Guangjian Yan, and Xiaoyu Zhang. "Analysis of NDVI and scaled difference vegetation index retrievals of vegetation fraction." Remote sensing of environment 101, no. 3 (2006): 366378.

Jiang, Zhangyan, and Alfredo R. Huete. "Linearization of NDVI based on its relationship with vegetation fraction." Photogrammetric Engineering \& Remote Sensing 76, no. 8 (2010): 965-975.

Kolb, T. E., M. R. Wagner, and W. W. Covington. 1991. "Forest Health from Different Perspectives." General Technical Report US Department of Agriculture, Forest Service.

Lausch, Angela, Stefan Erasmi, Douglas J. King, Paul Magdon, and Marco Heurich. 2016. "Understanding Forest Health with Remote Sensing-Part I-A Review of Spectral Traits, Processes and Remote-Sensing Characteristics." Remote Sensing. MDPI AG. doi:10.3390/rs8121029.

Lausch, Angela, Stefan Erasmi, Douglas J. King, Paul Magdon, and Marco Heurich. "Understanding Forest Health with Remote Sensing-Part II-A Review of Approaches and Data Models." Remote Sensing, 2017. https://doi.org/10.3390/rs9020129.

McKee, Thomas B., Nolan J. Doesken, and John Kleist. "The relationship of drought frequency and duration to time scales." In Proceedings of the 8th Conference on Applied Climatology, vol. 17, no. 22, pp. 179-183. Boston, MA: American Meteorological Society, 1993.

Penuelas, J., F. Baret, and I. Filella. "Semi-empirical indices to assess carotenoids/chlorophyll a ratio from leaf spectral reflectance." Photosynthetica 31, no. 2 (1995): 221-230. 
Pettorelli, Nathalie, Jon Olav Vik, Atle Mysterud, Jean-Michel Gaillard, Compton J. Tucker, and Nils Chr Stenseth. "Using the satellite-derived NDVI to assess ecological responses to environmental change." Trends in ecology \& evolution 20, no. 9 (2005): 503-510.

Pettorelli, Nathalie. The normalized difference vegetation index. Oxford University Press, 2013.

Raport de evaluare detaliată a biodiversității pentru ROSCI0267 Valea Roşie (Detailed report of biodiversity assessment for ROSCI0267 Red Valley). The project the „Impact of the ecosystems from the protected areas in the custody of the Bihor County Council and the Crisuri Country Museum over the main economic sectors" https://www.econaturabihor.ro/wpcontent/uploads/2013/02/Raport-final-A.3.-Evaluarebiodiversitate-ROSCI0267_AVENSAEPC_CJ-BIHOR.pdf

Raport privind starea pădurilor României în 2017. Ministerul Apelor şi Pădurilor. http://apepaduri.gov.ro/wpcontent/uploads/2014/07/Starea-p\%C4\%83durilor-\%C3\%AEnanul-2017.pdf

Reid, Shawna L., Joan L. Walker, and Abigail Schaaf. "Using multi-spectral landsat imagery to examine forest health trends at Fort Benning, Georgia." In In: Proceedings of the $18^{\text {th }}$ biennial southern silvicultural research conference. e-Gen. Tech. Rep. SRS-212. Asheville, NC: US Department of Agriculture, Forest Service, Southern Research Station. 614 p., vol. 212, pp. 601603. 2016.

Romocea, T., Oneț, A., Sabău, N. C., Onet, C., Herman, G. V., Pantea, E. (2018). "Change of the groundwater quality from industrial area Oradea, Romania, using Geographic Information Systems (GIS)". Environmental Engineering \& Management Journal (EEMJ), 17(9), 2189-2199.

Rouse, J.W., Hass, R.W., Schell, J.A., Deering, D.W., \& Harlan, J.C., 1973, "Monitoring the Vernal Advancement and Retrogradation (Greenwave Effect) of Natural Vegetation." NASA/GSFCT Type III Final report. Greenbelt, Maryland, USA.

Ryu, Youngryel, Galam Lee, Soohyun Jeon, Youngkeun Song, and Hyungsuk Kimm. "Monitoring multi-layer canopy spring phenology of temperate deciduous and evergreen forests using low-cost spectral sensors." Remote Sensing of Environment 149 (2014): 227-238.

Shah, Syed Haleem, Yoseline Angel, Rasmus Houborg, Shawkat Ali, and Matthew F. McCabe. "A Random Forest Machine Learning Approach for the Retrieval of Leaf Chlorophyll Content in Wheat." Remote Sensing 11, no. 8 (2019): 920.

Sims, Daniel A., and John A. Gamon. "Relationships between leaf pigment content and spectral reflectance across a wide range of species, leaf structures and developmental stages." Remote sensing of environment 81, no. 2-3 (2002): 337-354.

Verrelst, Jochem. Space-born spectrodirectional estimation of forest properties. 2010.

World Meteorological Organization, 2012: Standardized Precipitation Index User Guide (M. Svoboda, M. Hayes and D. Wood). (WMO-No. 1090), Geneva.
Xiao, Q., \& McPherson, E. G. (2005). Tree health mapping with multispectral remote sensing data at UC Davis, California. Urban Ecosystems. https://doi.org/10.1007/s11252-005-4867-7.

$\mathrm{Xu}$, Dandan, and Xulin Guo. "Compare NDVI extracted from Landsat 8 imagery with that from Landsat 7 imagery." American Journal of Remote Sensing 2, no. 2 (2014): 10-14. doi: 10.11648/j.ajrs.20140202.11

Xue, Jinru, and Baofeng Su. 2017. "Significant Remote Sensing Vegetation Indices: A Review of Developments and Applications." Journal of https://doi.org/10.1155/2017/1353691.

Yang, Hualei, Xi Yang, Mary Heskel, Shucun Sun, and Jianwu Tang. "Seasonal variations of leaf and canopy properties tracked by ground-based NDVI imagery in a temperate forest." Scientific reports 7 , no. 1 (2017): 1267.

http://natura2000.eea.europa.eu/Natura2000/SDF.aspx?site=RO SCI0267

https://earthexplorer.usgs.gov/

https://geoportal.ancpi.ro/

https://rp5.ru/Arhiva_meteo_\%C3\%AEn_Oradea_(aeroport) https://www.harrisgeospatial.com/Support/Self-Help-

Tools/Help-Articles/Help-Articles-

Detail/ArtMID/10220/ArticleID/16162/Vegetation-Analysis-

Using-Vegetation-Indices-in-ENVI

https://www.sentinel-hub.com/eoproducts/sipi-structureinsensitive-pigment-index 